\title{
Design Sizing of Cylindrical Worm Gearsets
}

A method for the design sizing task of cylindrical worm gearsets is presented that gives an estimate of the initial value of the normal module. Expressions are derived for the worm pitch diameter of integral and shell worms as well as for the active facewidth of the gear and the threaded length of the worm. An attempt is made to predict the contact strength of bronze materials against scoring resistance.

Four Examples of design sizing tasks of cylindrical worm gears are carried out using the approach presented and the results are compared with previous solutions from other methods. The results for first three examples show excellent comparisons with previous solutions of American Gear Manufacturers Association (AGMA) method. The results of the fourth example are slightly more conservative than those of DIN3999 but are practically similar. Therefore, it appears that a systematic, reliable and more scientifically based method for cylindrical worm drive design sizing has been developed.

Keywords: Contact, Strength, Stress, Sliding, Scoring, Sizing, Verification, Worm

\section{INTRODUCTION}

A worm gear drive consists of a worm and gear and is also called a wormset. A worm drive gives high transmission ratio, is of small size, has low weight and is compact in structure. It is the smoothest and most quiet form of gear drive [1] and can be designed as a self-locking transmission [2]. Wormsets are suitable in applications that must withstand heavy shock load or provide increased back-driving resistance [3]. A major disadvantage of worm drives is the relatively high slip velocity in the mesh which causes higher friction losses and thereby lower transmission efficiency. They must be able to dissipate the heat generated due to low efficiency so that in steady-state operation, a temperature that is not detrimental to the viscosity of the lubricant is maintained. Hence design of the housing and the selection of a lubricant and how it is supplied to the mesh are important aspects of worm drive design.

Two types of worm gearsets are cylindrical and globoid sets [4]. A cylindrical wormset is a single-enveloping or single-throated wormset that consists of a cylindrical worm screw with straight edges engaging a throated gear which partly wraps around the worm.

The wrapping provided by the throating helps to improve the contact between the worm and gear. Cylindrical wormsets can transmit power in the range of 0.04 $\mathrm{kW}-120 \mathrm{~kW}$ and globoidal gearsets can transmit more power [5].The focus in this study is on cylindrical wormsets, and further discussions are largely limited to them.

Worms are special power screws and the thread

Recevied: March 2019, Accepted: August 2019

Correspondence to: Dr. Edward E. Osakue

Department of Industrial Technology

Texas Southern University, Houston, Texas, USA

Email: osakueee@tsu.edu

doi:10.5937/fmet20010310

(C) Faculty of Mechanical Engineering, Belgrade. All rights reserved profiles may be trapezoidal, involute or some other profile [6]. The common worm thread profiles are designated as ZA, ZN, ZK, and ZI [7]. A special worm with concavely curved profile in the axial section is CAVEX which offers better contact conditions and higher load capacity [4]. Worm threads are made harder than the gears to facilitate better run-in between the pairs.

Worm gears are helical gears that are prone to scoring failure due to the high sliding velocity in the contact mesh compared to the other types of gears. To minimize failure by scoring, the contact stress is reduced compared to cylindrical gears. Also, contact strength correction for sliding velocity is made for many gear materials. The use of dissimilar material pair reduces likelihood of galling. Gear tooth failure due to fracture or breakage is rare in worm gearsets if well-designed [8]. Bending failure could be seriously damaging and should be avoided.

Design sizing is the task of obtaining the initial dimensions of a component, the initial layout sizes of a subassembly or assembly diagram. Such sizes are approximate and proper design verification must be done to finalize them. Additionally, design validation must be performed according to the agreement between the designer and the client. Worm profiles are more complex than involute tooth profiles and coupled with a lack of proper understanding of and adequate database on wear dependent failures makes the design of worm gearing empirical [2].

The objective of this study is to develop a more scientific and rational approach in the design sizing of cylindrical wormsets based on Hertzian contact stress analysis and mesh contact geometry. Accordingly, expressions are developed for estimating the basic dimensions of a worm gear and worm with the normal module as the characteristic size of the gearset and the active and nominal facewidths of the gear and worm. 
Also provided is an expression for estimating the contact strength of bronze materials from the compressive yield strength with an empirical modification factor for the mesh sliding speed.

\section{MATERIALS FOR WORM GEARSETS}

Sliding speed is relatively high in wormsets, necessitating materials with good frictional and run-in properties. Therefore, they are usually made of dissimilar materials in order to reduce frictional resistance and improve conformability [9]. Worms cannot be made very accurately, so soft worm gears are plastically deformed during initial run-in to facilitate good tooth contact [10]. Hence, the surface hardness of the worm threads should be substantially higher than that of the gear to facilitate run-in. Case-hardened worms are preferably used in medium-duty to heavyduty drives and they may be paired with any bronze and cast-iron gears. Thru-hardened steel and cast-iron worms are used in low-speed and light-duty drives and may be paired with phosphor bronze and cast-iron gears, but not heat-treated Aluminum or manganese bronze due to their high hardness. Heat treated aluminum and manganese bronzes should only be paired with case-hardened steel worm [11-17].

Worm gear teeth materials should be relatively soft and compliance to facilitate easy run-in and conformity with the hard worm thread surfaces. Worm gears may be made from bronze, steel, cast steel, cast iron, brass, and plastics. Phosphor bronze is preferably used when sliding speed is $10 \mathrm{~m} / \mathrm{s}$ and above. The most common phosphor bronze material choice is C90700 [18, 19]. Generally, aluminum, manganese, and silicon bronzes are used for heavy-duty, low- and medium-speed applications, preferably when sliding speed is below 10 $\mathrm{m} / \mathrm{s}$. Brass worm wheels are good for light-duty, lowspeed to medium-speed applications but they do not have very good frictional properties like the bronzes. Gray cast iron is good for sliding speeds of not more than $3 \mathrm{~m} / \mathrm{s}$ but ductile cast iron may be used up to $5 \mathrm{~m} / \mathrm{s}$. Plastics are used for very light loads and low speeds up to $2 \mathrm{~m} / \mathrm{s}$. Sand cast gears are mostly used for low speed drives and sand cast manganese bronze is used for lowspeed, heavy-duty applications [5, 7, 12, 13].

Selecting a worm gear material is very important in designing wormsets and the mesh sliding speed is the major determinant. Berezovsky et al. [6] and Chervilevsky [14] provided empirical expressions for an initial estimate of the sliding speed in the worm. A slight modification is made here to incorporate the application factor, which is often known or may be selected from references at the initial stage of a design project. The modified expressions are given in (1).

$$
\begin{aligned}
& V_{s}^{\prime} \approx 4 N_{1}\left[u K_{a} T_{1}\right]^{1 / 3} \times 10^{-4} \\
& V_{s}^{\prime} \approx 4 N_{1}\left[u K_{a} T_{2}\right]^{1 / 3} \times 10^{-4}
\end{aligned}
$$

Please refer to Nomenclature for the definition of symbols and design parameters. Subscript 1 refers to the worm, while subscript 2 refers to the gear.

\section{WORMSET LOADS}

The power transmitted by wormsets gives rise to loads like torques and forces on the gear and worm that are transmitted to the supporting shafts, bearings and housings. The speed ratio in wormsets is different from the ratio of the worm-gear pitch diameter to the worm pitch diameter. The speed ratio is obtained as:

$$
u=\frac{N_{1}}{N_{2}}
$$

The input and output powers are related as:

$$
P_{2}=\eta_{w} P_{1}
$$

The torque loads in the drive are:

$$
\begin{aligned}
& T_{1}=\frac{30 P_{1} \times 10^{3}}{\pi N_{1}} \\
& T_{2}=\frac{\eta_{w} P_{1} \times 10^{3}}{\pi N_{2}} \\
& T_{1}=\frac{T_{2}}{\eta_{w} u} \\
& T_{2}=u \eta_{w} T_{1}
\end{aligned}
$$

Fig. 1 shows the forces acting in a worm drive: Fig 1a shows the forces on the gear while Fig. 1b shows those on the worm. The forces are assumed to act on the pitch diameters of the worm and gear and the input is at the worm which is the most common configuration. The forces in Fig. 1 are:

$$
\begin{aligned}
& F_{t 1}=\frac{2 T_{1} \times 10^{3}}{d_{1}}=-F_{a 2} \\
& F_{t 2}=\frac{2 T_{2} \times 10^{3}}{d_{2}}=-F_{a 1} \\
& F_{r 2}=F_{t 2} \tan \phi_{t}=-F_{r 1} \\
& \phi=\tan ^{-1}\left[\frac{\tan \phi}{\cos \psi}\right]
\end{aligned}
$$

The normal plane of the wormset is assumed as the reference plane in $(7 b)$.
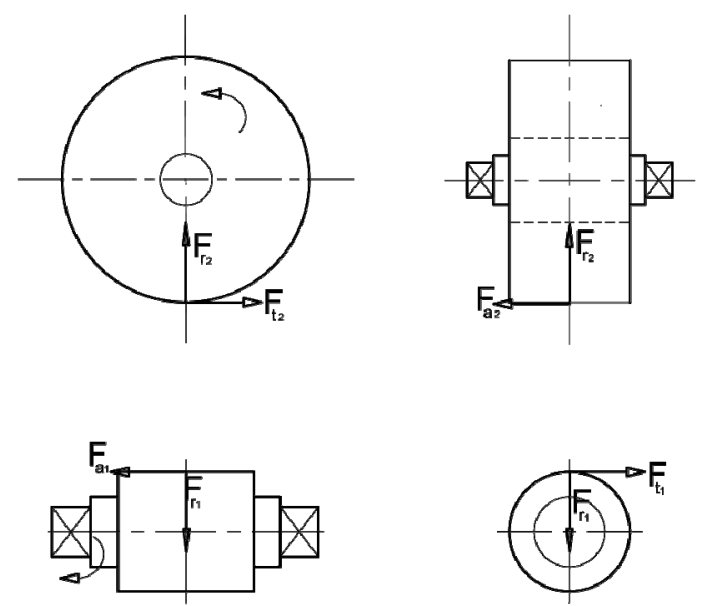

a) Gear forces

Fig. 1: Forces in worm drives 


\section{WORM LEAD ANGLE AND THREADS}

Lead angle of worms may vary from $9^{\circ}$ to $45^{\circ}$ and the average value is about $10^{\circ}$ [9], but a safe value is $12.5^{\circ}$ [20]. It is wise to limit lead angle to $6^{\circ}$ per thread [10, 21] so as to minimize the difficulty of designing production tools and producing accurate curvature on worm threads and gear teeth. From a theoretical analysis, an optimum lead angle for a compact design [20] may be estimated as:

$$
\gamma_{0}=\tan ^{-1}\left[\frac{1}{u}\right]^{1 / 3}
$$

Thus, for a worm with multiple threads, if the lead angle per thread is limited to $6^{\circ}$, then we have (9a). For the standard pressure angle of $20^{\circ}$, a minimum gear teeth number of 21 is recommended [16] and we could obtain (9b) as a guide.

$$
\begin{aligned}
& z_{1} \approx \frac{\gamma_{0}}{6} \\
& z_{1} \geq \frac{21}{u}
\end{aligned}
$$

For initial design estimate, (9a) and (9b) may be combined to yield (10a), so that the number of gear teeth can be obtained from (10a).

$$
\begin{aligned}
& z_{1} \approx \frac{1}{2}\left(\frac{21}{u}+\frac{\gamma_{0}}{6}\right) \\
& z_{2}=u z_{1}
\end{aligned}
$$

The nearest integer from (10a) may be used as a first choice. The other integer can be used for a second design and the two design results compared for a final selection. Common values of $z_{1}$ are $1,2,3,4,5$, and 6 for power drives but the preferred values are 1, 2, 3 and 4. The number of worm threads and gear teeth should be selected to get a hunting tooth for multiple threaded worms. A hunting tooth on the gear helps to distribute wear more evenly amongst gear teeth. This can be achieved by ensuring that the speed ratio is not an integer when multiple threaded worms are used. This is important because the number of threads on the hob for making the gear should match the number of threads on the worm. Higher efficiency is obtained by using higher number of threads; therefore, the use of the next integer from (10a) should be preferred. However, using the lower integer is acceptable if efficiency is not critical in a design situation.

\section{GEAR NORMAL MODULE AND DIAMETER}

Using the contact stress capacity model from [4], expressions for the normal module and gear pitch diameter are developed in this section.

\subsection{Contact Stress Capacity}

Worm profiles are more complex than involute tooth profiles. Though a number of attempts have been made by various researchers and organizations to develop a power rating system for worm gears, this has been somewhat elusive. The problem is that the long-term success of worm drives depends on many factors that are more difficult to adequately quantify compared to other types of gears [17]. However, Osakue and Anetor [4] recently developed a contact stress capacity model for cylindrical worm gears based on Hertzian contact stress analysis similar to those of cylindrical and bevel gearsets that addressed most of these complexities. The contact stress expression [4] may be rendered as:

$$
\sigma_{h}=\frac{\cos ^{2} \psi_{b} \times 10^{3}}{d_{2}} \sqrt{\frac{2.5 K_{H} K_{s} T_{2} E_{c}}{b_{g} \varpi_{t} \lambda_{t} \cos \psi}} \leq S_{H}
$$

where:

$$
\psi_{b}=\tan ^{-1}\left[\tan \psi \cos \phi_{t}\right]
$$

The basic spur gear diameter relationship with the pitch diameter of a helical gear is given in (12a) [4] and the gear effective facewidth is expressed as a function of the gear pitch diameter in (12b). (12c) is derived in section "Gear Facewidth and Factor", of the Appendix.

$$
\begin{aligned}
& d_{2}^{\prime}=d_{2} \cos \psi \\
& b_{g=}=\lambda_{b} d_{2} \\
& \lambda_{b} \approx \frac{2}{z_{2}} \sqrt{1+0.25 z_{2}}
\end{aligned}
$$

When (12a) and (12b) are substituted in (11a), (13) is obtained.

$$
d_{2}^{\prime} \geq 100\left\{\frac{2 K_{H} K_{s} T_{2} E_{c} \cos ^{4} \psi_{b} \cos ^{2} \psi}{\lambda_{b} \varpi \lambda_{c} S_{H}^{2}}\right\}^{1 / 3}
$$

The expression for the basic spur gear for the worm gear is given in (14a), [4]. In order to simplify (13), we make the conservative assumption that the helix angle is approximated by the base helix angle as indicated in (14b).

$$
\begin{aligned}
& d_{2}^{\prime}=m_{n} z_{2} \\
& \cos \psi \approx \cos \psi_{b}
\end{aligned}
$$

From [4], $\lambda_{c}$ is given by (15a) while $n_{t}$ is obtained from (15b).

$$
\begin{aligned}
& \lambda_{c}=\sqrt{0.5\left(n_{i}-2\right) z_{1} \geq 1} \\
& n_{t}=\frac{b_{w} \cos \psi}{\pi m_{n}}
\end{aligned}
$$

For initial design sizing, we can make the assumption of (16a) to obtain (16b) from (15a).

$$
\begin{aligned}
& n_{t}=4.5 \\
& \lambda_{c}=\sqrt{1.25 z_{1}}
\end{aligned}
$$

From [4], $\varpi_{t}$ is given by $(17 \mathrm{a})$.

$$
\varpi=\frac{\kappa_{1}+\kappa_{2}}{\pi \cos \phi_{n}}
$$




$$
\begin{aligned}
& \kappa_{1}=\frac{1}{\sin \phi_{n}} \\
& \kappa_{2}=0.5\left(\sqrt{\left(z_{2}+2\right)^{2}-\left(z_{2} \cos \phi_{n}\right)^{2}}-z_{2} \sin \phi_{n}\right)
\end{aligned}
$$

The expression for $K_{s}$ in (11) or (13) is given by (41a) and it cannot be accurately estimated at the beginning of a design task because some of the component factors depend on the size of the gear, gear tooth quality and other factors that are not known at the initial stages of sizing. However, $K_{a}$, one of the component factors, is often specified or can be selected from relevant references. Also, the worm thread profile type can be specified or chosen at the beginning of the design process so that $K_{w}$, another component of $K_{s}$, can be chosen. $K_{w}$ is 1.0 for $\mathrm{ZA}$ and $\mathrm{ZN}$ worm thread profiles, 0.8 for ZK and ZI profiles, and 0.6 for CAVEX thread profile [4]. For the purpose of initial sizing, $K_{s}$ may be approximated by $K_{s}^{\prime}$ as given in (18a).

$$
K_{s}^{\prime} \approx K_{a} K_{w}
$$

The design contact stress is:

$$
\begin{aligned}
& S_{H}=\frac{S_{c}}{n_{c}} \\
& n_{c} \geq 1.0
\end{aligned}
$$

For initial sizing, $n_{c}=1.0$ may be acceptable if work-hardening of the gear material after run-in is not considered.

In order to obtain an initial estimate of the normal module, substitute (14), (16b) and (18a) into (13) and simplify to arrive at Eq, (19a). Choose a standard normal module based on the initial estimate and calculate the initial pitch diameter of the gear from (19b).

$$
\begin{aligned}
& m_{n} \geq \frac{100 \cos ^{2} \psi_{b}}{z_{2}}\left\{\frac{2.5 K_{H} K_{s}^{\prime} T_{2} E_{c}}{\lambda_{b} \varpi_{t} S_{H}^{2} \sqrt{1.25 z_{1}}}\right\}^{1 / 3} \\
& d_{2}=\frac{m_{n} z_{2}}{\cos \psi}
\end{aligned}
$$

\subsection{Contact Strength Estimate}

Worm gears are susceptible to scoring failure [9, 18]. Scoring is a rapid wear of gear tooth surfaces due to lubricant film breakdown which allows metal-to-metal contact during motion. The high sliding speed in the worm leads to considerable heat generation. The lubricant film breaks down from overheating and the alternate welding and shearing of contacting surfaces result in metal particles being rapidly released from the surfaces [21]. Surfaces of scoring failure have a rough or matte texture that, under magnification, appear to be torn and plastically deformed [22]. Plastic deformation can occur only when a ductile material yields. Therefore, we may associate scoring failure with the yielding of contacting surfaces due to high contact stress and shearing due to the relative motion of the contacting surfaces. Specifically, it is supposed that gross local yielding will occur when the average Hertzian contact stress exceeds the dynamic contact yield strength [23]. On this premise, it is shown in section "Estimating Contact Strengths of Bronzes", of the Appendix that the nominal contact and adjusted contact strengths of bronze materials are approximately obtained as given in (20a) and (20b). (20c) is an empirically derived mesh sliding velocity adjustment factor.

$$
\begin{aligned}
& S_{c}^{\prime}=2.487 S_{y c} \\
& S_{c}=S_{c}^{\prime} Z_{v} \\
& Z_{v}=e^{-0.219 V_{z}^{1 / 3}}
\end{aligned}
$$

If $S_{y c}$ is the minimum compressive yield strength, the nominal reliability is $99 \%$ based on American Society of Testing Metals (ASTM) standard [13], and if it is the mean or average compressive yield strength, the nominal reliability is $50 \%$. The adjusted contact strength is obtained by multiplying the nominal contact strength by the mesh sliding velocity factor. An adjustment for durability is usually made for steel materials so it is logical to make a case for it for bronze materials. But this is not considered here, therefore, the durability factor is assumed to be unity. Also not considered is work-hardening effect on the gear after the run-in period. This has the ability to increase the contact strength of gear materials.

\section{WORM PITCH DIAMETER}

The worm pitch diameter is not related to the number of threads so it may have any suitable size which must be the same as the diameter of the hob used for cutting the worm gear [16]. Important considerations for worm shaft are mesh efficiency and shaft rigidity. Smaller worm pitch diameter gives higher mesh efficiency but larger worm pitch diameter gives better rigidity, therefore, a compromise should be sought in sizing worm pitch diameter. This situation allows some flexibility in sizing the worm but functionality is paramount. Deflection of the worm shaft under load can severely influence functionality as wear and failure results from excessive misalignment of the wormset when engaged. Hence lateral rigidity of shafts and housing of wormsets is very vital for the proper functioning of worm drives. According to Mott [15], the lateral deflection of worm shafts should be limited to the value given by (21a). However, (21b) is slightly more conservative and is adopted here.

$$
\begin{aligned}
& \delta_{0}=0.045 \sqrt{m_{a}} \\
& \delta_{0}=0.045 \sqrt{m_{n}}
\end{aligned}
$$

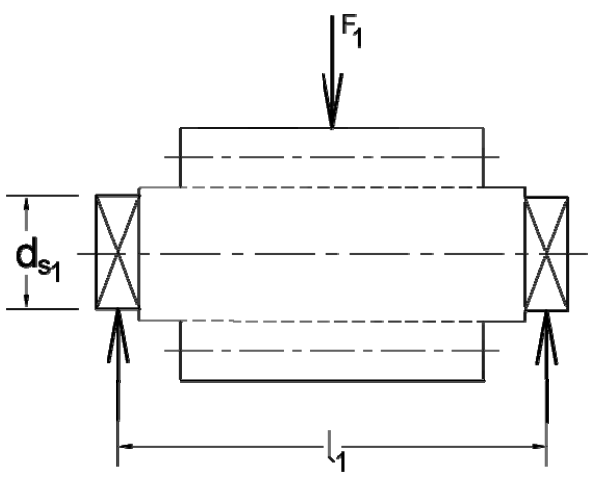

Fig. 2: Worm shaft configuration 
Fig. 2 shows a configuration of a worm shaft as a simply supported beam, under the influence of the resultant radial force. In Fig. 2, the maximum deflection of the shaft at mid span can be estimated as given in (22a).

$$
\begin{aligned}
& \delta=\frac{F_{1} l_{1}^{3}}{48 E_{s 1} I_{x 1}} \leq \delta_{0} \\
& F_{1}=\sqrt{F_{t 1}^{2}+F_{r 1}^{2}}
\end{aligned}
$$

(23a) is obtained from (22a), while (23b) is from elementary strength of materials.

$$
\begin{aligned}
& I_{x 1} \geq \frac{F_{1} l_{1}^{3}}{48 E_{s 1} \delta_{0}} \\
& I_{x 1}=\frac{\pi d_{s 1}^{4}}{64}
\end{aligned}
$$

According to Khurmi \& Gupta [25, p. 1118]; the distance between the worm shaft bearings may be approximated as the gear pitch diameter as indicated in (24a). By substituting (23b) and (24a) into (23a), we obtained (24b).

$$
\begin{aligned}
& l_{1} \approx d_{2} \\
& d_{s 1} \geq\left[\frac{30 F_{1} d_{2}^{3}}{\pi E_{s 1} \sqrt{m_{n}}}\right]^{1 / 4}
\end{aligned}
$$

It should be noted that the diameter from $(24 b)$ is the minimum uniform diameter between the bearing supports to meet the rigidity requirement. Therefore, this may be taken as the bearing bore diameter at the supports. Elsewhere between the bearing supports, the shaft diameter may be increased to enhance its rigidity. Reducing the shaft size between the bearing supports will reduce the rigidity of shaft and thus should be avoided.

A worm may be made integral with the worm shaft or made as a shell. The worm threads are cut directly on the shaft for integral worm, therefore, it may be assumed that the root diameter of the worm is equal to the shaft diameter. Hence the pitch diameter for integral worm is estimated as given by (25a). A shell worm is made separate and has a bore for mounting it on the shaft using splines, key, and pin. Therefore, material allowance must be made for keyway depth and also between the root radius of the worm and the keyway. The keyway depth is generally about $12.5 \%$ of shaft diameter. According to Shingley and Mischke [13], the minimum recommended thickness between keyway and root of the worm thread is half whole depth for noncase-hardened gears and worm-gears are usually not case-hardened. Hence the pitch diameter for a shell worm may be estimated as given by (25b).

$$
\begin{aligned}
& b_{2} \geq b_{g}+m_{n} \\
& d_{1} \geq(1+2 \times 0.125) d_{s 1}+2 \times 0.5 h_{f}+2 h_{f}
\end{aligned}
$$

Depending on the national or international standard $[6,7,9,13,26]$ used for proportioning wormsets, we have (26).

$$
\begin{aligned}
& h_{t} \leq 2.25 m_{n} \\
& h_{f} \leq 1.25 m_{n}
\end{aligned}
$$

When (26) is substituted into (25), the estimate for the pitch diameter of an integral worm is given by (27a) while that for a shell worm is given by (27b).

$$
\begin{aligned}
& d_{1} \geq d_{s 1}+2.5 m_{n} \\
& d_{1} \geq 1.25 d_{s 1}+4.75 m_{n}
\end{aligned}
$$

Generally, smaller pitch diameter worm screw gives higher efficiency and lower forces on the wormset. However, greater rigidity is obtained with larger pitch diameter of worm, because it allows larger face width for the gear. For initial sizing, the rigidity of the worm shaft may be strengthened by adding $10 \mathrm{~mm}$ to the estimates of (27) to arrive at (28) after some rounding.

$$
\begin{aligned}
& d_{1} \geq d_{s 1}+3 m_{n}+10 \\
& d_{1} \geq 1.25 d_{s 1}+5 m_{n}+10
\end{aligned}
$$

The initial estimate of the center distance is given by (29a). A standard center distance may be chosen based on this estimate so that the worm pitch diameter can be re-calculated as given in (29b). (29c) may be used as a check on the size of the worm pitch diameter [16].

$$
\begin{aligned}
& C^{\prime} \geq 0.5\left(d_{1}+d_{2}\right) \\
& d_{1}=2 C-d_{2} \\
& 0.5 C^{0.875} \leq d_{1} \leq 0.94 C^{0.875}
\end{aligned}
$$

Some worm gear design standards $[6,9,14,20]$ use a worm diameter factor which may be estimated as:

$$
z_{w} \geq \frac{d_{1}}{m_{n}}
$$

Common values of $z_{w}$ are $6,8,10,12,14,16,20$ but popular values are $8,10,12$, and 16 [7, 26, 27].

According to Dudley [21], common practice requires worm to be specified by the axial pitch and the popular metric axial pitches (mm) are 5, 7, 10, 15, 20, 30, and $40 \mathrm{~mm}$. If the worm is specified by the axial pitch, then the gear normal module which is likely not to be a standard value, is obtained as given by (31a). The pitch diameters of the gear and worm are then calculated as given by (31b) and (31c), respectively. (32) gives the center distance.

$$
\begin{aligned}
& m_{n}=\frac{p_{a} \cos \psi}{\pi} \\
& d_{2}=\frac{m_{n} z_{2}}{\cos \psi}=\frac{p_{a} z_{2}}{\pi} \\
& C=0.5\left(d_{1}+d_{2}\right)
\end{aligned}
$$

Once the pitch diameters of the wormset are chosen, then the lead angle can be calculated as given in (33a) or (33b). In the common wormset configuration where the shaft angle is $90^{\circ},(33 \mathrm{c})$ holds. 


\section{GEAR FACEWIDTH AND WORM THREADED LENGTH}

The active and nominal facewidths of the worm and gear are considered in this section. Fig. 3 shows a cylindrical wormset mesh while Fig. 4 shows maximum interference of the worm thread with the gear.

\subsection{Gear Face Width}

According to Shigley and Mischke [13], the useful portion of a worm gear facewidth is obtained if a tangent line is drawn through the worm pitch circle diameter to intersect the tip or outside circle diameter of the worm. Referring to the right diagram of Fig. 3, this geometric description leads to line $\mathrm{DD}^{\prime}$ for the useful or active facewidth of the gear and is considered to be always safe [21]. Hence the active facewidth for the gear is:

$$
b_{g}=2 D B=2 \sqrt{(O D)^{2}-\left(O B^{\prime}\right)^{2}}
$$

That is:

$$
\begin{aligned}
& b_{g}=2 \sqrt{m_{n}\left(d_{1}+m_{n}\right)} \\
& b_{2} \geq b_{g}+m_{n}
\end{aligned}
$$

The nominal facewidth of the gear should be slightly more than the active or active length, so (35b) is suggested.
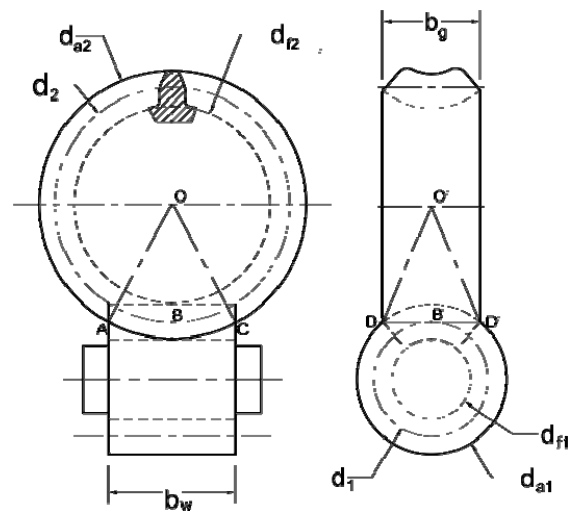

Fig. 3: Cylindrical wormsets basic dimensions

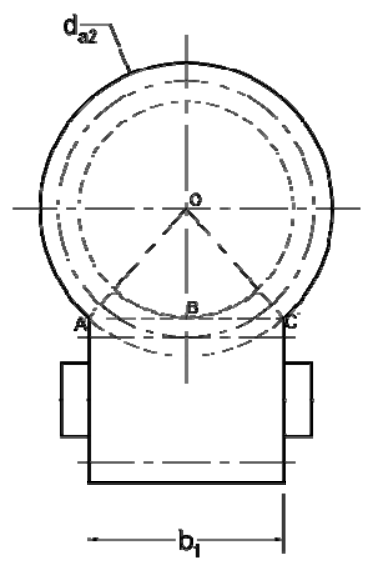

Fig. 4: Nominal Threaded length of worm

\subsection{Worm threaded length}

The idea of Shigley and Mischke [13], used to obtain the active gear facewidth may be applied to the worm thread length also. That is, the active screw length of the worm may be defined by a tangent line through the gear pitch circle diameter and its intercepts with the gear tip circle diameter, that is, length $\mathrm{AC}$ in the left diagram of Fig. 3. Therefore, the active screw length is estimated as

$$
\begin{aligned}
& b_{w}=2 A B=2 \sqrt{(O A)^{2}-(O B)^{2}}= \\
& =2 \sqrt{\left(o .5 d_{2}+m_{n}\right)^{2}-\left(0.5 d_{2}\right)^{2}}
\end{aligned}
$$

That is:

$$
b_{w}=2 \sqrt{m_{n}\left(d_{2}+m_{n}\right)}
$$

Fig. 4 shows the maximum interference of the worm threaded length with the gear. The line $\mathrm{A}^{\prime} \mathrm{C}^{\prime}$ is tangent to the working diameter circle of the gear, not the root circle since some clearance is required between the outside radius of the worm and the root radius of the gear for proper functioning of the gearset. This is the minimum nominal threaded length of the worm if it is required that the thread on the worm extends over the interference zone defined by line $\mathrm{A}^{\prime} \mathrm{C}^{\prime}$. Referring to Fig. 4 and noting that $O A^{\prime}=0.5 d_{2}+m_{n}$ and $O B^{\prime}=0.5 d_{2}-m_{n}$ then:

$$
\begin{aligned}
& b_{1} \geq 2 A^{\prime} B^{\prime}=2 \sqrt{\left(O A^{\prime}\right)^{2}-\left(O B^{\prime}\right)^{2}} \\
& b_{w} \geq 2 \sqrt{\left(0.5 d_{2}+m_{n}\right)^{2}-\left(0.5 d_{2}-m_{n}\right)^{2}}
\end{aligned}
$$

That is:

$$
\begin{aligned}
& b_{1} \geq 2 \sqrt{2 m_{n} d_{2}} \\
& b_{1} \geq 2 \sqrt{2 m_{n} d_{2}}+m_{n}
\end{aligned}
$$

(38b) is a provided as a suggestion, because some clearance and chamfer allowances are necessary for manufacturing. An alternative method is provided in the Appendix for estimating the nominal length of the worm.

\section{DESIGN VERIFICATION}

Due to the high sliding contact speed in the worm, the efficiency of wormsets cannot be ignored in power transmission because the output from the drive depends on it. The sliding speed may be used to estimate the kinetic coefficient of friction in the worm. The sliding speed is given by (39a). For a ground case-hardened steel worm mated with quality phosphor bronze gear that is well-lubricated, the kinetic friction coefficient in the worm may be approximated as given in (38b) [28].

$$
\begin{aligned}
& V_{s}=\frac{\pi d_{1} N_{1} \times 10^{-3}}{60 \cos \gamma} \\
& \zeta_{k}=\frac{0.04 k_{m}}{V_{s}^{0.25}} \leq 0.15 k_{m}
\end{aligned}
$$

The value of $k_{m}$ for ground case-hardened steel worm and quality phosphor bronze is 1.0 ; it is 1.15 for aluminum bronze, and 1.30 for cast iron gear [28]. If the worm is unground, $30 \%$ to $50 \%$ increase in friction value is not unlikely $[7,16]$. A ball worm gear mechanism can help in considerably reducing the mesh friction [39]. 
The efficiency of the worm is obtained as [29]:

$$
\eta_{w}=\frac{\cos \phi_{n}-\zeta_{k} \tan \gamma}{\cos \phi_{n}+\zeta_{k} \cot \gamma}
$$

The service load factor and Hertz contact stress factor can be evaluated as given below [4].

$$
\begin{aligned}
& K_{s}=K_{a} K_{v} K_{m} K_{c} K_{w} \\
& K_{H}=K_{f} K_{p} K_{x}
\end{aligned}
$$

The contact stress in the mesh is estimated [4] using (42a) and the apparent Hertz contact stress design factor is estimated using (42b).

$$
\begin{aligned}
& \sigma_{H}=\frac{\cos _{b}^{2} \psi \times 10^{3}}{d_{2}} \sqrt{\frac{2 K_{H} K_{s} T_{2} E_{c}}{b_{2} \varpi_{t} \lambda_{c} \cos \psi}} \\
& n_{H}=\frac{S_{c}}{\sigma_{H}} \geq n_{c}
\end{aligned}
$$

$n_{H^{-}}$apparent Hertz contact stress design factor

Though $n_{c}=1.0$ may be acceptable for initial sizing if work-hardening of the gear material after run-in is not considered, however, $n_{H}$ should be greater than unity for acceptable design.

Based on (11a), the output torque rating of a cylindrical wormset, assuming the thermal rating is adequate, is:

$$
T_{2}=\frac{\varpi_{t} \lambda_{t} b_{g} d_{2}^{2} S_{H}^{2} \cos \psi \times 10^{6}}{2.5 K_{H} K_{s} E_{c} \cos ^{4} \psi_{b}}
$$

The output and input power ratings, respectively, are:

$$
P_{2}=\frac{\pi N_{2} T_{2} \times 10^{-3}}{30}, P_{1}=\frac{P_{2}}{\eta_{w}}
$$

\section{APPLICATION EXAMPLES}

The design procedure presented in the previous sections is tested in four (4) design examples in which the task is to determine the sizes of the wormsets to meet some specified requirements. The problem statements in the examples have been paraphrased and the design parameters have been converted to metric units by the authors where necessary. The examples are taken from previous published works by other authors. Examples 1 to 3 were previously designed using AGMA method $[15,16]$ while Example 4 was previously designed using DIN3999:2002 method [30].

\subsection{Design Problems}

This section presents four examples in cylindrical wormset design sizing.

\section{Example 1}

Design a $7.5 \mathrm{~kW}$ worm-gear speed reducer with 11:1 speed ratio for a lumber mill planer speed drive for 3 to 10 -hour daily use. A squirrel-cage induction motor drives the planer feed at $1720 \mathrm{rpm}$. Assume that $K_{a}=1.25$ [16].

\section{Example 2}

Design a $5.5 \mathrm{~kW}$ worm-gear speed reducer with 17.33:1 speed ratio for 3 to 10 -hour daily use if the worm shaft rotates at $1750 \mathrm{rpm}$ (revolutions per minute). Assume that the pressure angle is $20^{\circ}$ and $K_{a}=$ 1.0 [15].

\section{Example 3}

Develop a design for a worm-gear speed reducer with an input power of $0.75 \mathrm{~kW}$ and $56: 1$ speed ratio using an electric motor running at $1725 \mathrm{rpm}$. Assume that $K_{a}=1.25$ and the gear is made from sand cast bronze [16].

\section{Example 4}

Develop a design for a worm-gear speed reducer with an output torque of $588 \mathrm{Nm}$ and speed ratio of 20.5 using an electric motor running at $1500 \mathrm{rpm}$. Assume that $K_{a}=1.0$ and the gear is made from bronze with a yield strength of $180 \mathrm{MPa}$ and nominal contact strength of $520 \mathrm{MPa}$ [30].

\subsection{Design Solutions}

The equations presented in the previous sections were coded in Microsoft Excel for computational efficiency. The spreadsheet has two pages of two sections per page. The first page has a material selection and strengths estimation sections. The second page has design sizing and design verification sections. Iteration during design verification involved choosing a standard module, estimating the lead angle, calculating the gear pitch diameter, calculating the worm pitch diameter, recalculating lead angle and gear pitch diameter. Iteration is stopped when the lead angle used to calculate the gear pitch diameter is the same as the lead angle obtained using the worm pitch diameter. That is, when helix angle of (19b) is equal to the lead angle of (33a) or (33b). Two to four iterations were needed for acceptable solutions. After convergence, the gear active and nominal facewidths and worm active and nominal lengths are calculated. The contact stress and Hertz contact stress design factor are then calculated. Table 1 is a summary of the input data from the problem statements and some initial estimates used to initiate design iteration. Table 2 compares the results from the approach presented with previous solutions obtained using AGMA method. Table 3 compares the results from the present approach with previous solutions obtained using DIN 3999 method. Table 4 shows the preferred solutions for the design Examples, while Table 5 shows the values of some selected design parameters.

\section{DISCUSSIONS}

Based on the mesh sliding speed initial estimates in Table 1 row 6, low tin phosphor bronze or aluminum bronze is a candidate material for the design. Since sand cast phosphor bronze is chosen for the gear while hardened steel material is chosen for the worm in the previous solutions; the same was chosen so that the 
results from the present design approach may be compared with the previous ones. The composite elastic modulus for steel and bronze material combination is $160 \mathrm{GPa}$ [31] and is shown in row 7 of Table 1 . The nominal contact strength for sand cast phosphor bronze (Table A1), was evaluated to be $377 \mathrm{MPa}$ using (20a). The initial design strength was then obtained by applying the velocity factor based on the initial sliding velocity. The initial estimates for worm threads are show in row 8 of Table 1 and are 2.97, 2.37, and 1.41 respectively for Example 1, Example 2 and Example 3. The value for Example 4 is 2.18. Two (2) or 3 threads are feasible for Example 1, though 3 appears more appropriate, 2 or 3 may be used for Example 2 and 1 or 2 may be used for Example 3.

In order to compare results with previous solutions, 2 threads were chosen for Example 1, 3 for Example 2, and 1 for Example 3. With these set of thread values, initial estimates of the normal module of the gears were computed and the results are shown in row 9 of Table 1. Based on the initial normal module value estimates, standard module values were chosen [16] and Table 2 shows the final results after 2 to 4 iterations as explained previously. The second set of thread values: 3 for Example 1, 2 for Example 2 and 1 for Example 3 (the value of 2 threads was not used since one thread is usually used for speed ratios over 30) were used to obtain the initial normal modules shown in row 10 of Table 1. These are the values used to generate the results shown in Table 4 for the preferred design solutions. For Example, 4, two (2) threads seem more appropriate and were used to obtain the results in Table 3. The previous solution was based on two threads for this Example.

Table 2 compares the results from the current design approach with previous solutions based on AGMA approach. It is remarkable that there is an exceptional match between the results. It is clear from this table, that the current approach is very accurate because it yields almost identical results with the previous solutions. Table 3 compares the results from the current approach with previous solutions based on DIN3996:2002 [30] approach. Column 2 of Table 3 shows the results based on the yield strength of $180 \mathrm{MPa}$ that was used to obtain the nominal contact strength of $446 \mathrm{MPa}$ ( (20a)) and column 3 shows the results based on nominal contact strength of $520 \mathrm{MPa}$ which is given in the original problem. Column 4 of Table 3 is the previous solution from the cited reference. The results based on the provided nominal strength are practically the same as the previous solution results, indicating that the current approach gives acceptable results if nominal contact strength is given or known. The solution based on the yield strength (column 2 of Table 2) should be used when the nominal contact strength of the gear material is unknown. As can be seen, this gives results that are slightly more conservative than that in column 3 . This is not necessarily a weakness since in the preliminary design phase, available data is limited and the nominal contact strength may not be available while the yield strength may be available or can be determined easily. Therefore, a conservative solution at the initial stages of design may minimize the number of iterations that can yield optimized results later. The mesh sliding velocity factor and nominal contact strength reported for Example 4 are 0.851 and $520 \mathrm{MPa}$, respectively [30]. The corresponding values obtained from (20c) and (20a) are 0.717 and $446 \mathrm{MPa}$, respectively. Therefore, the design contact stress from the current design approach is $320 \mathrm{MP}$ while it is $443 \mathrm{MPa}$ in the previous solution. It thus appears that the estimates from the current design approach are conservative, though just one case is insufficient for making a definitive conclusion. However, the design solutions obtained with $320 \mathrm{MPa}$ do not differ that much from those from $443 \mathrm{MPa}$ : compare columns 2 and 4 data in Table 3 . The mesh sliding velocity factor estimates from (20c) were used in both current solutions.

Table 1: Input Data Summary and Initial Estimates

\begin{tabular}{|l|c|c|c|c|}
\hline \multicolumn{1}{|c|}{ Design Parameter } & Example 1 & Example 2 & Example 3 & Example 4 \\
\hline Input power (kW) & 7.5 & 5.5 & 0.75 & 5.12 \\
\hline Input speed (rpm) & 1720 & 1750 & 1725 & 1500 \\
\hline Speed ratio & 11 & 17.33 & 56 & 20.5 \\
\hline Normal pressure angle (deg.) & 20 & 20 & 20 & 20 \\
\hline Application factor & 1.25 & 1.00 & 1.25 & 1.00 \\
\hline Sliding velocity (m/s) - (1) & 5.71 & 5.63 & 4.57 & 4.25 \\
\hline Composite elastic modulus (GPa) & 160 & 160 & 160 & 160 \\
\hline $\begin{array}{l}\text { Worm threads: initial estimate (for Table } \\
\text { 2 \& Table 3) - (10a) }\end{array}$ & 2.97 & 2.37 & 1.41 & 2.18 \\
\hline $\begin{array}{l}\text { Normal module (mm): initial estimate (for } \\
\text { Tables 2 and 3) - (19a) }\end{array}$ & 8.5 & 3.6 & 3.6 & 3.8 \\
\hline $\begin{array}{l}\text { Normal module (mm): initial estimate (for } \\
\text { Table 4) - (19a) }\end{array}$ & 5.9 & 5.6 & 3.6 & 4.2 \\
\hline
\end{tabular}

Table 2: Comparison of Current Previous Solutions by AGMA Method

\begin{tabular}{|l|c|c|c|c|c|c|}
\hline \multirow{2}{*}{\multicolumn{1}{|c|}{ Parameter }} & \multicolumn{2}{c|}{ Example 1 } & \multicolumn{2}{c|}{ Example 2 } & \multicolumn{2}{c|}{ Example 3 } \\
\cline { 2 - 7 } & Current & Previous & Current & Previous & Current & Previous \\
\hline Normal module (mm) & 10 & 11.32 & 4 & 4.1 & 3.5 & 3.17 \\
\hline Worm threads & 2 & 2 & 3 & 3 & 1 & 1 \\
\hline Gear teeth & 22 & 22 & 52 & 52 & 56 & 56 \\
\hline Worm lead angle (deg) & 17.64 & 20.89 & 13.89 & 14.01 & 4.78 & 4.77 \\
\hline Gear pitch diameter (mm) & 231 & 266.8 & 214 & 220.14 & 197 & 177.8 \\
\hline Worm pitch diameter (mm) & 65 & 63.5 & 50 & 50.8 & 42 & 38.1 \\
\hline
\end{tabular}




\begin{tabular}{|l|c|c|c|c|c|c|}
\hline Gear face active width $(\mathrm{mm})$ & 55 & 38.1 & 30 & 31.8 & 26 & 25.4 \\
\hline Center distance $(\mathrm{mm})$ & 148 & 165.15 & 132 & 135.5 & 120 & 108 \\
\hline Mesh friction factor & 0.020 & 0.019 & 0.022 & 0.022 & 0.023 & 0.025 \\
\hline Efficiency (\%) & 93 & 94.2 & 90.9 & 90.9 & 77.3 & 75.6 \\
\hline
\end{tabular}

Table 3: Comparison of Current and Previous Solutions by DIN3999 Method

\begin{tabular}{|l|c|c|c|}
\hline \multirow{2}{*}{\multicolumn{1}{|c|}{ Parameter }} & \multicolumn{3}{c|}{ Example 4 } \\
\cline { 2 - 4 } & Current* & Current $^{* *}$ & Previous \\
\hline Normal module (mm) & 4.5 & 4 & 3.905 \\
\hline Worm threads & 2 & 2 & 2 \\
\hline Gear teeth & 41 & 41 & 41 \\
\hline Worm lead angle (deg) & 11.28 & 10.24 & 12.53 \\
\hline Gear pitch diameter (mm) & 188 & 167 & 164 \\
\hline Worm pitch diameter (mm) & 46 & 45 & 36 \\
\hline Gear face active width (mm) & 31 & 28 & 30.83 \\
\hline Center distance (mm) & 117 & 106 & 100 \\
\hline Mesh friction factor & 0.023 & 0.023 & 0.0234 \\
\hline Mesh efficiency (\%) & 88.8 & 87.5 & 90.0 \\
\hline *Nominal strength from (20) used. **Nominal strength from reference used. \\
\hline
\end{tabular}

Table 4: Preferred Current Solutions for Examples

\begin{tabular}{|l|c|c|c|c|}
\hline \multicolumn{1}{|c|}{ Parameter } & Example 1 & Example 2 & Example 3 & Example 4 \\
\hline Normal module (mm) & 6 & 6 & 3.5 & 4.5 \\
\hline Worm threads & 3 & 2 & 1 & 2 \\
\hline Gear teeth & 34 & 35 & 56 & 41 \\
\hline Worm lead angle (deg) & 17.46 & 12.84 & 4.78 & 11.28 \\
\hline Gear pitch diameter (mm) & 214 & 216 & 197 & 188 \\
\hline Integral worm pitch diameter (mm) & 54 & 54 & 42 & 46 \\
\hline Gear face active width (mm) & 38 & 38 & 26 & 31 \\
\hline Gear nominal face width (mm) & 45 & 45 & 32 & 35 \\
\hline Worm active threaded length (mm) & 75 & 75 & 55 & 60 \\
\hline Worm nominal threaded length (mm) & 110 & 110 & 85 & 90 \\
\hline Center distance (mm) & 134 & 135 & 120 & 117 \\
\hline Mesh efficiency (\%) & 93.2 & 90.5 & 77.3 & 88.8 \\
\hline
\end{tabular}

\section{CONCLUSIONS}

Table 4 shows the preferred solutions. The differences between Table 2 and Table 4 are that solutions to Example 1are based on three (3) threads instead of two (2) and those for Example 2 are based on two (2) threads instead of three (3). Three threads solution is preferred for Example 1 because the gear size is smaller, so it will be cheaper to produce since phosphor bronze is expensive due to the tin content. The gear sizes are about the same for Table 2 and Table 4 solutions for Example 2 however, the two threads solution (Table 4) is preferred because the worm is stiffer and the gear module is bigger. Therefore, Table 4 solution will give better bending fatigue resistance and the larger worm size will provide better rigidity. The very close prediction from the current design approach to the previous solutions in Tables 2 and 3 is a great encouragement, but may not be generalized without further investigations.

Table 5 provides extra parameter data for better understanding of the solutions provided. Row 1 of Table 5 shows the sliding velocity which is used to choose the gear tooth quality number of row 2. Lower values of internal overload factor and better-quality grades were chosen for higher sliding velocities. Worm gears are typically manufactured by hobbing with a hob or cutting tool very similar to the worm that the gear mates with [32]. They can be shaved for enhanced quality, so achieving grades 10 to 7 will be economical and minimize the internal overload factor. Row 3 of Table 5 gives the values of the service load factors. The evaluation of this parameter requires choosing a gear tooth profile quality number. This was guided by choosing a quality number that will give an internal overload factor of not more than 1.3 for a spur gear which may be achieved by finish hobbing or shaving after hobbing.

Row 4 shows the sliding velocity factor used to modify the nominal contact strength to obtain the adjusted contact strength of row 5. Row 6 of the table shows the evaluated contact stresses and the last row of Table 5 shows the apparent Hertz contact design factors for the design Examples. The Hertz contact stress design factors are all more than unity, indicating acceptable designs. The contact stress capacity model for cylindrical worm gears [4] is modified for design sizing task. Using scientific knowledge, engineering experience and engineering judgment; available design information and data are synthesized into a method for cylindrical worm gear sizing not currently available. Formulas are developed for the normal module of the worm gear, worm pitch diameter for integral or shell worm, the active and nominal facewidths of the gear and worm and the threaded length of the worm. This approach eliminates the conventional trial and error method for the virtually initial sizing of the worm. Some iteration is sometimes required before achieving acceptable size values for the worm and gear pitch diameters but the number of iterations are few than conventional methods. 
Table 5: Some Design Parameter Estimates for Preferred Solutions

\begin{tabular}{|l|c|c|c|c|}
\hline \multicolumn{1}{|c|}{ Parameter } & Example 1 & Example 2 & Example 3 & Example 4 \\
\hline Sliding velocity (m/s) & 5.16 & 5.08 & 3.81 & 3.684 \\
\hline Gear quality number (ISO) & 8 & 8 & 9 & 9 \\
\hline Service load factor & 1.611 & 1.276 & 1.610 & 1.289 \\
\hline Sliding velocity factor & 0.674 & 0.691 & 0.715 & 0.717 \\
\hline Adjusted contact strength (MPa) & 257.3 & 257.8 & 266.6 & 320.0 \\
\hline Contact stress (MPa) & 204 & 216.4 & 216.50 & 301.9 \\
\hline Apparent contact stress design factor & 1.26 & 1.19 & 1.25 & 1.06 \\
\hline
\end{tabular}

The design approach developed in this paper is similar to those of cylindrical and bevel gears. However, the high contact sliding speed in the mesh of wormsets makes scoring a more probable failure mode. Consequently, the contact strength of worm gear materials must be corrected for the sliding speed. An attempt is made to predict the contact strength from the compressive yield strength of bronze materials against scoring resistance. The solutions obtained from the contact strength model are encouraging based on the Examples considered.

Four design Examples are carried out using the presented approach and the results are compared with previous solutions from different references in Tables 2 and 3. There appears to be excellent match between the solutions from the current design approach and the previous ones based on AGMA method shown in Table 2. The comparison of the solutions in Table 3 indicates that solutions from the current design method are slightly more conservative with respect to those of DIN3999:2002. Certainly, more Examples are necessary for further verification of the design approach presented. However, it appears that the approach is sufficiently accurate enough to be acceptable for the preliminary design of cylindrical wormsets because of the excellent comparison with well-established design standards. Consequently, it seems that a more scientific and reliable method for cylindrical worm drive design has emerged.

\section{ACKNOWLEDGEMENTS}

The authors gratefully acknowledge that this study was supported in parts with funds from the College of Science, Engineering, and Technology (COSET) Research Fund and the University Faculty Development Fund of Texas Southern University, Houston, Texas.

\section{REFERENCES}

[1] Walsh, R. A., Electromechanical Design Handbook, 3rd ed. McGraw Hill, New York, 2000, p. 8.78 .

[2] Collins, J. A., Busby, H., Staab, G. H., Mechanical Design of Machine Elements and Machines: A Failure Prevention Perspective, 2nd ed., John Wiley and Sons, New York, 2010.

[3] Murray, Murray, M. (2010), Total System Efficiency, Power Transmission Engineering, www.powertransmission.com, p. $16-23$.

[4] Osakue, E. E., Anetor, L., Contact Stress Capacity Models For Cylindrical Worm Gears, Australian Journal of Mechanical Engineering (AJME), Manuscript No. EATJ-D-18-00701, 2018.
[5] MITCalc, Worm_Gear.xls: http://www.mitcalc. com/doc/gear4/help/en/gear4.htm, (Accessed September 2018).

[6] Berezovsky, Y., Chernilevsky, D. Petrov, M., Machine Design, MIR Pub., Moscow, 1988.

[7] Maitra, G. M., Fundamentals of Toothed Gearing: Handbook of Gear Design, 2nd ed., McGraw Hill, Delhi, 2013.

[8] Norton, R. L., Machine Design: An Integrated Approach, 2nd. Edition, Prentice-Hall, Upper Saddle River, New Jersey, 2000.

[9] Bhandari, V. B., Design of Machine Elements, 3rd ed. McGraw-Hill, New Delhi, 2010.

[10] Bhandari, V. B, Introduction to Machine Design, McGraw-Hill, New Delhi, 2013.

[11] Winsmith, The Speed Reducer Book: A Practical Guide to Enclosed Gear Drives, Peerless-Winsmith, 1980.

[12]KHK, Calculations of Gear Dimensions https://khkgears.net/new/gear_knowledge/gear _technical_reference/calculation_gear_dimensi ons.html, Kohara Gear Industry Co., Ltd., Saitama-ken, 332-0022, Japan. (Accessed September, 2018).

[13] Shigley, J. E. and Mischke, C. R., Standard Handbook of Machine Design, 2nd Edition, McGraw-Hill, 1996.

[14] Chernilevsky, D., A Practical Course in Machine Design, MIR, Moscow, 1990Chernilevsky,

[15] Mott, R. L., Machine Elements in Mechanical Design, 4th Edition, Pearson, Prentice Hall, Singapore, 2006.

[16] Budynas, R. G. \& Nissbett, J. K., Shigley's Mechanical Engineering Design, 9th Edition, McGraw Hill Education, 2010.

[17] Schmid, S. R., Hamrock, B. J. \& Jacobson, B. O., Fundamentals of Machine Elements, 3rd ed., CRC Press, New York, 2014.

[18] Juvinall, R. C. and Marshek, K. M., Juninall's Fundamentals of Machine Component Design, SI, Wiley, Singapore, 2017.

[19] National Bronze, Properties of Phosphor Bronze, www.nationalbronze.com/C90700_Gear_Bron ze.php

[20] Khurmi, R. S. and Gupta, J. K., A Textbook of Machine Design, Eurasia Pub. House, New Delhi, 2015, p. 1104. 
[21] Dudley, D. W., Handbook of Practical Gear Design, CRC Press, 2004.

[22] Shipley, E. E., (1967), Gear Failures: How to recognize them, what causes them, and how to avoid them, https://www.xtek.com/wpcontent/uploads/2018/05/xtek-gear-

failures.pdf, (Accessed September 2018).

[23] Errichello R. L. and Muller, J, How to analyze gear failures https://www.researchgate.net/publication/2256 02159_How to analyze gear_failures, (Accessed September 2018).

[24] Ishibashi et al. (1984), Akira Ishibashi, Shigeru Hoyashita, Hidehiro Yoshino, Studies on Upper Limit of Surface Durability of Phosphor Bronze, Bulletin of JSME, Vol. 27 (1984) No. 225 P 592-600, http://doi.org/10.1299/jsme 1958.27.592

[25] Gope, P. C. Machine Design: Fundamentals and Applications, PHI Learning, Delhi, 2014.

[26] Dobrovolsky, Zablonsky, K., Mak, S., Radchik, A., \& Erlikh, L. Machine Elements, Moscow, 1965.

[27] Cherlivevsky, D. Lavrova, E. and Romanov, V., Mechanics for Engineers, MIR, Moscow, 1984.

[28] RoyMech: Gears- Gear Efficiency, www.roymech.co.uk/Useful_Tables/Drive/Gear_Efficie ncy.html, (Accessed August, 2018).RoyMech, 2018,

[29] Childs, P. R. N., Worm Gears: Mechanical Design Engineering Handbook, Butterworth Heinemann Elsevier, Boston, 2014.

[30] KISSsoft, Bevel Rating Along AGMA 2003 in KISSsoft;

[31] https://wenku.baidu.com/view/a3dbd8649b6648 d7c1c7460e.html, (Accessed September 2018).

[32] Osakue, E. E., Simplified Spur Gear Design, Proceedings of International Mechanical Engineering Congress and Exposition 2016 IMECE, Paper Number IMECE2016-65426, November 11-17, Phoenix Arizona, USA, 2016.

[33] Gearmotion: Advantages of Worm Gears, Syracuse, NY 13209 USA, https://gearmotions.com/advantages-of-worm-gears/, (Accessed September 2018).

[34] Sundararajan, G. Energy Absorbed During the Oblique Impact of Hard Balls Against Ductile Target Materials, Int'1 Journal of Impact Engineering, Vol. 9, No. 3, 343 - 358, 1990,

[35] Chang, W. R. and Ling, F. F. Normal Impact Model of Rough Surfaces, Journal of Tribology, Vol. 114, 439 - 447, 1992.

[36] Review of Plane Stress and Plane Strain Elasticity http://w3.uacg.bg/UACEG_site/acadstaff/userfi les/study_bg_162_L_02_Plane_Elsticity.pdf, (Accessed September 2018).
[37] Rowe, p. 5-6, 17, Rowe, W., Elements of Metal Working Theory, Edward Arnold, London, 1979, pp. 5 - 6, 17.

[38] Osakue, E. E. and Anetor, L., A Comparative Study of Contact Stress from Different Standards for Some Theoretical Straight Bevel Gear Pairs, Int'l Journal of Research in Engineering and Technology, Vol. 07, Issue 8, 2018.

[39] Osakue, E. E. and Anetor, L., Comparing Contact Stress Estimates of Some Straight Bevel Gears with ISO 10300 Standards, Proceedings of International Mechanical Engineering Congress and Exposition 2016 IMECE, Paper Number IMECE2018-86573, November 9-15, Pittsburgh, Pennsylvania, USA, 2018.

[40] Kocak, S., An Innovative Design for a Ball Worm Gear Mechanism, International Journal of Engineering Technologies, Vol. 3, No 4, pp. $230-234,2017$.

\section{NOMENCLATURE}

HVN Hardness: Vicker's Number

1 subscript 1 refers to worm

2 subscript 2 refers to gear

$\operatorname{Inv}(\phi)$ involute function

$b_{1} \quad$ nominal length of worm thread (mm)

$b_{2} \quad$ nominal facewidth of gear

$b_{g} \quad$ active facewidth of gear

$b_{m} \quad$ worm thread manufacturing allowance $(\mathrm{mm})$

$b_{w} \quad$ active length of worm thread (mm)

$b_{g} \quad$ active gear face width

c root diameter clearance $(\mathrm{mm})$

C center distance ( $\mathrm{mm}$ )

$C^{\prime} \quad$ center distance initial value $(\mathrm{mm})$

$d \quad$ pitch diameter $(\mathrm{mm})$

$d_{a} \quad$ addendum diameter $(\mathrm{mm})$

$d_{f} \quad$ dedendum diameter $(\mathrm{mm})$

$d_{2}^{\prime} \quad$ worm gear basic spur gear pitch diameter $(\mathrm{mm})$

$d_{s 1} \quad$ worm shaft diameter $(\mathrm{mm})$

$d_{r 1} \quad$ worm root diameter $(\mathrm{mm})$

$d_{A 2} \quad$ gear blank diameter $(\mathrm{mm})$

E elastic modulus (GPa)

$E_{c} \quad$ composite or effective elastic modulus (GPa)

$E_{s 1} \quad$ elastic modulus of worm shaft material (MPa)

$F_{t} \quad$ transmitted (tangential) force (N)

$F_{r} \quad$ radial force (N)

$F_{a} \quad$ axial force (N)

$F_{1} \quad$ resultant radial load on shaft $(\mathrm{N})$ 
$h_{f} \quad$ dedendum $(\mathrm{mm})$

$h_{t} \quad$ whole or total depth (mm)

$I_{x 1} \quad$ area moment of inertia of shaft $\left(\mathrm{mm}^{4}\right)$

$k_{m} \quad$ material friction factor

$K_{s} \quad$ service load factor

$K_{a} \quad$ application or external overload factor

$K_{v} \quad$ internal overload or dynamic factor

$K_{m} \quad$ mounting or mesh overload factor

$K_{r} \quad$ rim backup factor

$K_{c} \quad$ contact quality factor

$K_{w} \quad$ worm thread profile factor

$K_{f} \quad$ contact form factor

$K_{p} \quad$ profile modification factor

$K_{x} \quad$ crowning or ellipticity factor

$K_{H} \quad$ Hertz contact stress factor

$K_{a} \quad$ application factor

$K_{s}^{\prime} \quad$ initial estimate of $K_{s}$

$l_{1} \quad$ distance between bearing supports

or shaft span (mm)

$m_{a} \quad$ axial module $(\mathrm{mm})$

$m_{n} \quad$ normal module of worm gear ( $\left.\mathrm{mm}\right)$

$n_{t} \quad$ number of gear teeth over active length of worm thread

$n_{c} \quad$ minimum contact strength design factor

$N \quad$ rotational speed (rpm)

$p_{H} \quad$ mean contact stress (MPa)

$P \quad$ power transmitted $(\mathrm{kW})$

$r_{b} \quad$ blanking radius $(\mathrm{mm})$

$s_{\mathrm{x}} \quad$ gear tooth modification factor residual

$S_{c}^{\prime} \quad$ nominal contact strength (MPa) $S_{c}$ service or adjusted contact strength (MPa)

$S_{H} \quad$ design contact stress (MPa)

$S_{y c} \quad$ static compressive yield strength ( $\left.\mathrm{MPa}\right)$

$S_{y c}^{*} \quad$ dynamic contact strength (MPa)

$T \quad$ Torque transmitted $(\mathrm{Nm})$

$u \quad$ actual speed ratio

$V_{s} \quad$ sliding velocity in mesh $(\mathrm{m} / \mathrm{s})$

$V_{s}^{\prime} \quad$ initial estimate of mesh sliding velocity in worm $(\mathrm{m} / \mathrm{s})$

$\mathrm{X}$ gear tooth modification factor

$z_{2} \quad$ number of teeth on gear

$z_{w} \quad$ worm diameter factor

$Z_{v} \quad$ mesh sliding velocity factor $\varpi_{t} \quad$ basic spur transverse contact ratio

$\lambda_{c} \quad$ contact ratio coefficient

$\lambda_{b} \quad$ active gear facewidth factor

$\kappa_{1} \quad$ contact length factor for rack

$\kappa_{2} \quad$ contact length factor for pinion

$\delta \quad$ maximum deflection ( $\mathrm{mm})$

$\delta_{o} \quad$ permissible maximum deflection ( $\mathrm{mm}$ )

$\psi \quad$ helix angle of gear (deg.)

$\psi_{b} \quad$ base helix angle of gear (deg.)

$\phi \quad$ generic pressure angle (deg.)

$\phi_{t} \quad$ transverse pressure angle (deg.)

$\phi_{n} \quad$ normal pressure angle (deg.)

$\phi_{w t} \quad$ working transverse pressure angle (deg.)

$\gamma_{o} \quad$ optimum lead angle of worm (deg.)

$\gamma \quad$ lead angle of worm (deg.)

$\eta_{w} \quad$ efficiency of worm

$\varsigma_{k} \quad$ sliding or kinetic mesh friction coefficient in worm

$v \quad$ Poisson's ratio

$\sigma_{H} \quad$ maximum Hertz contact stress $(\mathrm{MPa})$

\section{ПРОЈЕКТОВАЊЕ ВЕЛИЧИНЕ ПАРА ЦИЛИНДРИЧНИХ ПУЖНИХ ЗУПЧАНИКА}

\section{Е.Е.Осакуе, Л.Анетор}

Приказан је метод за пројектовање величине пара цилиндричних пужних зупчаника који даје процену иницијалних вредности нормалног модула. Изведени су изрази за пречник корака преносника код интегралног и шкољкастог пужа као и за ширину зупчаника и дужину навоја код пужа. Приказан је покушај предикције отпорности на зарибавање у зависности од степена контакта материјала од бронзе. Дата су четири задатака за пројектовање величине пара цилиндричних пужних зупчаника применом описаног метода и извршено је поређење са резултатима добијеним другим методама. Резултати добијени у прва три задатка показали су изврсност у слагању са решењима које даје метод Удружења америчких произвођача преносника. Резултати добијени у четвртом задатку се незнатно разликују од оних које прописује DIN3999. Према томе, изгледа да смо развили систематски, поуздан и научно заснован метод за пројектовање величине пара цилиндричних пужних зупчаника.

\section{APPENDIX}

\section{A1 Gear Facewidth and Factor}

The expression for the gear active facewidth is given in (A1a) while (A1b) is for the gear facewidth factor. 


$$
\begin{aligned}
& b_{g}=2 \sqrt{m_{n}\left(d_{1}+m_{n}\right)}=2 m_{n} \sqrt{1+z_{w}} \\
& \lambda_{b}=\frac{b_{g}}{d_{2}}=\frac{b_{g}}{m_{a} z_{2}}=\frac{2 \cos \gamma}{z_{2}} \sqrt{1+z_{w}}
\end{aligned}
$$

According Berezovsky et al. [6], $z_{w}$ should be at least $22 \%$ of the number of gear teeth for rigidity purposes and (A2a) expresses this observation. Hence, if $z_{w}$ is assumed to be $25 \%$ of the number of gear teeth, we obtain (A2b).

$$
\begin{aligned}
& z_{w} \geq 0.22 z_{2} \\
& \lambda_{b} \approx \frac{2}{z_{2}} \sqrt{1+0.25 z_{2}}
\end{aligned}
$$

\section{A2 Gear blank outside diameter}

Three types of gear blanks are in use: those integral with shaft, those with web and rimmed gear, those with ring gear bolted or shrink-fitted on carrier wheel. Minimum backup thickness for gear teeth is 1.25 to 1.5 times whole depth of gear [13]. The half angle subtended by the gear nominal facewidth is given in (A3a) while (A3b) gives the blanking radius of the gear.

$$
\begin{aligned}
& \alpha=\sin ^{-1}\left(\frac{b_{2}}{d_{a 1}}\right) \\
& r_{b}=\left(0.5 d_{f 1}+c\right) \cos \alpha
\end{aligned}
$$

The blank diameter of the gear is governed by (A4a) and (A4b) is a suggested estimate.

$$
\begin{aligned}
& 0.5 d_{A 2}>C-r_{b} \\
& d_{A 2} \geq 2\left(C-r_{b}\right)+0.5 m_{n} 1
\end{aligned}
$$

\section{A3 Estimating Contact Strengths of Bronzes}

Worm gears are prone to scoring and seizure failures [6, 18]. Scoring is a rapid wear of gear tooth surfaces due to lubricant film breakdown which allows metal-to-metal contact during motion. The lubricant film breaks down from overheating and the alternate welding and shearing of contacting surfaces result in metal particles being rapidly released from the surfaces [22]. Surfaces of scoring failure have a rough or matte texture that, under magnification, appear to be torn and plastically deformed [23]. Plastic deformation can occur only when a ductile material yields, therefore, we may associate scoring failure with the yielding of contacting surfaces. Scoring is aggravated by high contact stress and temperature because they make welding easier since material yield strength decreases with increasing temperature. Hence, minimizing the mesh contact stress and temperature is important in reducing the risk of scoring failure. Gear operations are associated with vibrational impact due to local acceleration and deceleration during meshing. Therefore, yielding of gear surfaces should be related to the dynamic contact yield strength. The dynamic contact yield strength may be defined for a body in contact with respect to the dynamic tensile yield strength [33]. For low-velocity impact, the dynamic yield strength is approximately equal to the static yield strenFME Transactions gth and the dynamic contact yield strength of ductile materials may be obtained as given in (A5a), [34]. The Poisson's ratio for copper alloys is approximately 0.35 [24], so (A5b) gives the dynamic contact strength of these materials.

$$
\begin{aligned}
& S_{y c}^{*}=(1.282+1.15 v) S_{y c} \\
& S_{y c}^{*}=1.6845 S_{y c}
\end{aligned}
$$

Note that for ductile materials the compressive yield strength is approximately equal to tensile yield strength.

\section{A3.1 Contact Failure Criterion (Ductile Material)}

According to Ishibashi et al. [24] surface cracks can only propagate if the mean Hertzian stress is high enough. Therefore, it may be assumed that surface contact failure occurs when the mean Hertzian stress is equal to or exceeds the static contact yield strength in static conditions or the dynamic contact yield strength in dynamic conditions as for gears. For scoring failure, welding can follow yielding due to high contact stress and the heat that is generated from high frictional resistance due to metal-to-metal contact. The relative motion between the contacting surfaces facilitates shearing of welded patches which makes the surfaces rougher. The mean Hertzian contact pressure for line contact in gears is given in (A6a) while (A6b) expresses the failure condition.

$$
\begin{aligned}
& p_{H}=\frac{\pi}{4} \sigma_{H} \\
& p_{H} \geq S_{y c}^{*}
\end{aligned}
$$

(A7a) is obtained by combining (A6a) and (A6b). When (A5b) is substituted in (A7a), (A7b) is obtained.

$$
\begin{aligned}
& S_{c}^{\prime}=\sigma_{H}=\frac{4.0}{3.1416} S_{c}^{*}=1.2734 S_{y c}^{*} \\
& S_{c}^{\prime}=1.2734 S_{y c}
\end{aligned}
$$

The composite or active elastic modulus of two bodies in Hertzian contact is obtained as in (A8a) [31]:

$$
\begin{aligned}
& E_{c}=\frac{2 E_{1} E_{2}}{E_{2}\left(1-v_{1}^{2}\right)+E_{1}\left(1-v_{2}^{2}\right)} \\
& \frac{2}{E_{c}}=\frac{1-v_{1}^{2}}{E_{1}}+\frac{1-v_{2}^{2}}{E_{2}}
\end{aligned}
$$

(8b) is the same as (8a), but it reveals the nature of $E_{c}$ as being the harmonic mean of the plane strain moduli [35] of the materials in Hertzian contact. Consequently, plane strain deformation can be assumed in pitting or scoring failure of gear drives. Under plane strain deformation, the yield strength which is sometimes called the constrained yield stress; is about 1.155 times the yield strength in uniaxial tension [36]. Therefore, Eq, (A7b) may be modified as:

$$
S_{c}^{\prime}=1.155 \times 2.145 S_{y c}=2.478 S_{y c}
$$


Table A1: Mechanical Properties of Phosphor Bronze (C90700) Grades at $20^{\circ} \mathrm{C}$ [19]

\begin{tabular}{|c|l|c|c|c|c|}
\hline Treatment & \multicolumn{1}{|c|}{ Processing } & $\begin{array}{c}\text { Min. Tensile } \\
\text { Strength (MPa) }\end{array}$ & $\begin{array}{c}\text { Min. Yield } \\
\text { Strength (MPa) }\end{array}$ & $\begin{array}{c}\text { Hardness } \\
(\text { HVN) }\end{array}$ & $S_{c}^{\prime}(\mathrm{MPa})$ \\
\hline M01 & Sand casting & 303 & 152 & 85 & 377 \\
\hline M07 & Continuous casting & 276 & 172 & - & 426 \\
\hline M02 & Centrifugal casting & 345 & 193 & 100 & 478 \\
\hline M02 & Centrifugal casting & 379 & 207 & 108 & 513 \\
\hline M05 & Pert. Mold casting & 379 & 207 & 108 & 513 \\
\hline Fatigue strength: $170 \mathrm{MPa}$ & \multicolumn{5}{|l}{ Elastic modulus: $105 \mathrm{GPa}$} \\
\hline
\end{tabular}

Table A1, shows the mechanical properties of the most popular bronze material grades used in worm gears. In column 6 of Table A1, estimates of the nominal contact strength based on (A9) for the material grades are shown. The nominal reliability is assumed as $99 \%$ because of the use of the minimum yield strength, since ASTM defines minimum strength at 99\% reliability [13]. If average compressive yield strength is used, then the nominal reliability will be $50 \%$.

\section{A3.2 Sliding Velocity Adjustment Factor}

The influence of the high sliding contact speed in worm drives must be taken into account in estimating contact resistance. For instance, Ishibashi et al. [24], observed that a $20 \%$ drop in bronze contact strength was observed when sliding was introduced into the contact zone. Also, it may be inferred from Dudley [21] that the "running" contact strength for hardened steel or cast-iron worm and phosphor bronze gear is about $50 \%$ of the "static" contact strength.

Similarly, the running contact strength of cast iron worm and cast iron gear is about $42.64 \%$ of the static contact strength. Maitra [7], provides an empirical formula that may be used to assess the safety of worm drives for thermal capacity which incorporates a material factor modifier that is a function of the sliding velocity.

Table A2: Material Sliding Velocity Factor [7, P. 4.28, Table 4.10]

\begin{tabular}{|c|c|c|}
\hline $\begin{array}{c}\text { Sliding Velocity } \\
(\mathrm{m} / \mathrm{s})\end{array}$ & $\begin{array}{c}\text { Material } \\
\text { Factor }\end{array}$ & Adjustment Factor \\
\hline 0.1 & 1.12 & 0.8929 \\
\hline 0.5 & 1.19 & 0.8403 \\
\hline 1.1 & 1.25 & 0.8000 \\
\hline 2.0 & 1.33 & 0.7519 \\
\hline 4.0 & 1.47 & 0.6803 \\
\hline 8.0 & 1.61 & 0.6211 \\
\hline 12.5 & 1.67 & 0.5988 \\
\hline 16.0 & 1.70 & 0.5882 \\
\hline
\end{tabular}

The data is reproduced in columns 1 and 2 of Table A2. In column 3 of Table A2, the data value is the reciprocal of column 2 data. Based on the range of the sliding velocity in the table, it may be safely assumed that the gear material is bronze. The data in column 3 of Table A2 is used to derive an empirical sliding velocity adjustment factor expression for the contact strength of bronze worm gears that is given in (A10a). The empirical expression facilitates coding in Excel spread sheet.

The adjusted or service contact strength of bronze worm gear material is given in (A10b).

$$
\begin{aligned}
& Z_{v}=e^{-0.219 V_{s}^{1 / 3}} \\
& S_{c}=S_{c}^{\prime} Z_{v}=S_{c}^{\prime} e^{-0.219 V_{s}^{1 / 3}}
\end{aligned}
$$

\section{A4 Selecting Gear Tooth Quality}

The service load factor $K_{s}$ for worm drives may be estimated by a multiplicative rule as provided in (41a) [4]. Methods of estimating the component factors of $K_{s}$ are presented in [4]. As a guide for gear tooth profile quality selection, commercial quality gears may have $1.25<K_{v}<1.5$, premium quality gears may have $1.15 \leq K v \leq 1.25$, and precision quality gears may have $K_{v}$ [37]. In these categories, lower values would mean higher processing cost. For high speed applications, especially those above $20 \mathrm{~m} / \mathrm{s}$, methods that account for gear material properties, mass and inertia of the gears, and actual tooth profile errors should be used to estimate, $K_{v}$ [15]. To facilitate run-in, worm gears should preferably be made to premium quality levels and worms should be made to at least one tooth quality grade higher than the gear. That is, if the quality number for the gear is 8 , the quality number of the worm should be 7 at the minimum. Note that better quality facilitates better run-in of gearset and thus more reliable and better service.

\section{A5 Hertz Contact Stress Factor}

The Hertz contact stress factor accounts for gear profile geometry and is expressed as [37,38]:

$$
K_{H}=K_{f} K_{p} K_{x}
$$

where:

$$
\begin{aligned}
& K_{f}=\frac{2}{\pi \sin 2 \phi_{n}} \\
& K_{p}=\frac{\tan \phi_{t}}{\tan \phi_{w t}}
\end{aligned}
$$

For addendum or center distance modified gears:

$$
\begin{aligned}
& \operatorname{inv} \phi_{w t}=i n v \phi_{t}+2 \tan \phi_{n}\left[\frac{s_{x}}{z_{1}+z_{2}}\right] \\
& \operatorname{inv} \phi=i n v \phi-\phi(\mathrm{rad} .)
\end{aligned}
$$

(13a) applies to balanced profile modification on pinion and gear while (13b) applies to unbalanced profile modification.

$$
s_{x}=x_{1}+x_{2}=0
$$




$$
s_{x}=x_{1}+x_{2}=0
$$

\section{A6.0 Worm Nominal Length: Alternative Method}

The active length of worm thread should be increased by 25 to $30 \mathrm{~mm}$ for the feed marks produced by vibrating grinding wheel as it leaves the thread root [20]. Berezovsky et al. [6] suggest adding $3 m_{a}$ to $b_{w}$ for hobbed and ground worms while Chernilevsky [14] suggests adding $25 \mathrm{~mm}$ for $m_{a}<10 \mathrm{~mm}, 35$ to $40 \mathrm{~mm}$ for $10 \mathrm{~mm} \leq m_{a} \leq 16 \mathrm{~mm}$ and $50 \mathrm{~mm}$ for $m_{a}>16 \mathrm{~mm}$ based on manufacturing considerations. Therefore, a manufacturing allowance of 25 to $50 \mathrm{~mm}$ appears adequate for most cylindrical wormsets. The nominal length of thread on the worm may then be estimated as:

$$
\begin{aligned}
& b_{1} \geq b_{w}+b_{m} \\
& b_{m}=3 m_{n} \geq 25 \mathrm{~mm}
\end{aligned}
$$

